\title{
Exploratory Research on the Blended Listening and Speaking Teaching Model under the Background of Cultivating the Internationalized Talents
}

\author{
Lijuan Zhang \\ Xi’an International University, Xi'an Shaanxi, 710077
}

Keywords: Internationalization; Cultivation of the Talents; Blended Listening and Speaking Teaching Model

\begin{abstract}
Nowadays, as the development of the internationalization, Chinese students communicates with the foreign students much more than anytime before, under this background, the Chinese government puts forward stricter requirements to the colleges. At the some time, as the fast development of the multi-value and the multi-ideology, the colleges also put forward the new requirements on the English teaching, so as to cultivate the internationalized talents. In order to fulfill the requirement of cultivating the internationalized talents, the colleges should accelerate the reform of English teaching, and take the exchange between the Chinese education and the foreign education as the educational foundation, then to discuss and research on the curriculum system, teaching model, and the class model, so as to search a new breakthrough and try their best to construct the new teaching system of the college English; at the some time, the colleges should cultivate the students' overall abilities that is the requirement of the internationalization in the new times, so as to strengthen the pertinence and effectiveness of the college English education. Basing on the back ground of cultivating the internationalized talents, this thesis makes an exploratory research on the blended listening and speaking teaching model.
\end{abstract}

In the times of economic globalization, the internationalized development of the college has become a very issue that the public concern a lot. In recent years, China is accelerating the reform of the higher education, and the teachers of the colleges are seeking the new teaching model for their lessons. During the development of internationalization, the colleges are transforming their previous educational goals that are to cultivate the diversified high-quality talents to the goals of cultivating the students with the internationalized high-quality talents, so as to promote the further educational and the economic development of China by cultivating more talents ${ }^{[1]}$. Under this background, as one of the most important curricula of the college, and the key factor of cultivating the internationalized talents, the college English teaching is facing many challenges, it should be reformed as soon as possible because the traditional teaching model is not suitable for the situation of the Reform and Opening up policy in China and the requirement of cultivating the internationalized talents. Therefore, in order to meet the rising demand to the high-quality talents in the international human resources market, China has put forward the stricter requirements to the colleges for improving their educational qualities. For following the situation, to innovate the teaching model is one of the important tasks to the colleges at present.

\section{The significance of applying the blended listening and speaking teaching model under the background of cultivating the internationalized talents}

The development of the economy drive the rapid reform and development of China, it is the developmental demand of the society. One of the essential objectives of the social development is to cultivate the talents according to the developmental demands of our country in the new times so as to meet the demand of constructing a stronger motherland. In order to meet the demand of cultivating the internationalized talents, as the key curriculum in the college educational system, college English teaching should be reformed overall in the situation that the internationalization is coming, only by this could we solve the brand new challenge ${ }^{[2]}$. From the macro and historical perspective, we can find that the college English teaching always integrates with the textbook, and 
it is lack of the support of the relevant modern auxiliary teaching methods such as the network and the Big Data technology in the past, it is very hard to get to some teaching resources except in class; while as the development of internationalization, there are many new approaches for teaching or learning English, so that the English teaching and learning are not be restricted in class any more, English teaching could be launched by various ways ${ }^{[3]}$. Both the teachers and the students could get to the educational resources by the brand new methods without the restriction of time and space, and then they implement or receive the educational resources much easier. By these conveniences in the network times, the blended teaching model of college English is put forward; this model is a brand new teaching model that integrates the contents and features of the traditional teaching model with the new teaching methods. By the application of the new model, teachers and students could take the best of the effectiveness of it so that the students could learn the proper English knowledge at the appropriate time so as to improve their learning efficiencies and their English abilities.

\section{The new features of the college English teaching under the background of cultivating the internationalized talents}

It is the inevitable trend to diversify the teaching model, and it is the requirement of the times and the educational development. During this process, the international exchange is the most important factor. In the new times, the students are eager to improve themselves when they face the impact of the culture, economy, and ideology. Nowadays, the international exchange has been a universal method for the students to take part in the relevant overseas activities, and for the teachers to share their learning and teaching experiences; these methods are propitious to the adjustment and reformation of the colleges' whole teaching systems; at the some time, the students could learn more knowledge about the world, enrich themselves and learn more about the foreign cultures, so as to make progress on their studies and personal abilities. Nowadays, the college students can take part in a lot of international activities such as the international exchange conference and the transnational competition in campus or at the other places. They also can have an overseas practice trip so as to lay a solid foundation for the development of their own, and then, to make contributions to the development of the motherland.

As the increase of the overseas exchange, the students' ideas on English learning could be changed. The college teachers' academic abilities of internationalization is becoming strong, this is an obvious feature of the college English education under the background of internationalization. According to the relevant researching results, we can find out that most of the college teachers have overseas academic background; especially, in some majors such as English, Russian, and French etc, the proportion of the overseas teachers is more than 50\%, and some English teachers of the famous university are foreigners, all these above promote the international exchanges of the colleges, and inject the new blood into the educational cause in the new times ${ }^{[4]}$.

\section{The construction of the blended listening and speaking teaching model of English under the background of cultivating internationalized talents}

The blended listening and speaking teaching model originates from the blended learning which is a brand new ideological system and a kind of innovative teaching strategy. The prominent feature of the blended teaching is "appropriate". In the "appropriate" time; by the "appropriate" learning method or technique; be consistent with the "appropriate" learning style; teaching the "appropriate" knowledge to the "appropriate" students; by these methods above, the students' abilities could be improved maximally so that they could get to a sound learning results ${ }^{[5]}$. The blended teaching model integrates the advantages of the traditional teaching model with the advantages of the modern network technology, so the blended teaching model could bring the "appropriate" teaching results at the "appropriate" time, it could not only actualize the leading, inspiring and administrative functions of the teachers during the English teaching, but also promote the students to learn English actively and on their own initiative, so as to take the best of the students' creativity and improve their English abilities. Although the blended teaching model contains lots of relevant knowledge, 
but "listening" and "speaking" are the main parts of it. To integrate the teaching model with the theoretical knowledge, the extracurricular learning resources, and the proper blended listening and speaking learning circumstance, the students could improve their English by the advantages of the blended teaching model.

The teachers should carefully prepare the relevant teaching materials for the students, choose the proper listening and speaking learning resources, establish clear teaching objectives, and set up scientific teaching theme, and then effectively integrate these resources that are dispersed and visible together, at the some time, edit the wonderful English listening and speaking resources that are in accord with the native English, so as to ensure the learning efficiency of the following study ${ }^{[6]}$. The goal of the blended listening and teaching model is to let the students learn more knowledge in class, it is different from the traditional teaching model; it could provide more space to the students for their self-learning and take the best of the students' activeness. Therefore, after establish the teaching goal and the teaching theme; the teachers should arrange the teaching task according to the teaching requirement. For example, the teachers share the teaching contents such as the micro-lecture and the database that is related to the listening and speaking English that the students will learn with the students via network; the teachers should assign the learning task to the students so that the students could learn the materials anywhere in their spare time, so as to fulfill the learning task. After this process of preparation, the learning efficiency in class would be sound. During the self-learning process, the students could ask for helps to their teachers via network, or solving the problems by the resources in network.

Before the formal class, the college listening and speaking English teachers should establish some network groups or official accounts in the network platforms such as QQ or Wechat etc, so as to share the teaching resources with the students during the different teaching phases; for the students, they could follow the guidance of the teachers, and get to the useful resources from their teachers. The official accounts are the foundation for the teachers adopting the blended teaching model in the formal class. According to the certain teaching goal and teaching theme, the teachers should assign the teaching tasks to the students via the official account; the students must log in their accounts and then prepare and learn the relevant learning resources such as pictures, video and audio materials etc. During the preparation, the students should take some notes about their problems and the difficult knowledge, after this, they could discuss the simple issues in the groups with their classmates; for the difficult issues they could not solve by their own, they could ask for their teachers in the following class. There are three important segments in the listening and speaking English teaching those are topic introduction, listening input, and speaking output. The teachers must take the best of the mobile electronic technology, mobile phone, computer, panel computer all are the important and efficient auxiliary teaching tools which are convenient for teaching and learning. After class, the students also could download the courseware for reviewing; they also could make some records when they practice their listening and speaking English, the records could to be one of the evaluating criterions of their marks.

\section{Conclusion}

Nowadays, as the rapid development of the internationalization of the college education, the educational reform of China has been accelerated, at the some time, the extent of overseas exchange is expanding step by step. Under this background, more and more foreign students come to China, and China also outputs the educational resources to other countries, and also, the number of the Chinese students study abroad is increasing year by year. Facing the development of internationalization and the demand of cultivating the internationalized students, the college English teachers should explore the new teaching model; improve the teaching quality, so as to promote the further development of the students, the colleges, and our motherland.

\section{Acknowledgement}

Pro:The periodical achievement of 2017 planned project approved by the 13th Five-year Plan of 
Education and Science of Shaanxi Province:the Construction and Empirical Research of College En glish Teaching Mode Based on POA Theory under the Background of the International Talent Culti vation——Take the Example of Xi'an International University （Project Number:SGH17H421）.

\section{References}

[1] Yang Fenhong, Zhang Shibo, Ke Haiping, Jiang Wenyin, Fan Luning. Empirical Research on the Blended Teaching Model that is Theoretically and Practically Supported by Wechat----Take the Course Advanced Office Automation for Example[J]. The Chinese Journal of ICT in Education, 2016, 06:50-53.

[2] Liu Xiaomei. Exploration and Research on the New Blended Audio-visual Teaching Model of English----Take Beijing University of Chemical Technology for Example[J]. Modern Educational Technology, 2016, 11:100-106.

[3] Wu Jing. Discuss on the English Blended Teaching Model of the Local Colleges in “Internet Plus” Times[J]. Journal of Hengyang Normal University, 2016, 05:164-167.

[4] Huang Min. Research on Improving the English Teaching of the Art Students----the Blended Teaching Model that Integrates the MOOC and the Traditional Class Teaching[J]. Journal of Jinan Vocational College, 2015, 02:56-59.

[5] Zhang Yi, Gao Jian. Research on the Blended Teaching Model of the College English----Take a School-based Research for Example[J]. The Chinese Journal of ICT in Education, 2015, 18:55-58+87.

[6] Shu Dingfang. To Follow the National Developmental Strategy and Cultivate the Internationalized Talent----Deliberation on the Reformation and Reposition of the College English Teaching in the New Times[J]. Foreign Language Research, 2013, 06:90-96. 